\section{¿CÓMO PENSÓ \\ TULIO HALPERIN DONGHI \\ LA POLÍTICA DE ENTREGUERRAS?}

TULIO HALPERIN DONGHI'S

INTERWAR PERIOD

ROY HORA ·

Investigador Independiente del CONICET con sede en el Departamento de Ciencias Sociales de la Universidad Nacional de Quilmes

E-mail: rhora@unq.edu.ar

\section{Resumen}

Este ensayo analiza de qué manera Tulio Halperin Donghi abordó la historia política argentina del período 1916-1943. De acuerdo a este historiador, una exploración cuidadosa de la etapa que corre entre el final del orden oligárquico y el ascenso del peronismo -y en particular de la así llamada «década infame»- resulta fundamental para comprender las causas de la inestabilidad institucional de la segunda mitad del siglo XX. El artículo explora de qué modo Halperin Donghi analizó este período, enfatiza las diferencias de enfoque con sus estudios sobre el siglo XIX, y pone de relieve sus principales argumentos.

\section{Registro bibliográfico}

HORA, ROY «¿Cómo pensó Tulio Halperin Donghi la politica de entreguerras?», en: ESTUDIOS SOCIALES, revista universitaria semestral, año XXVIII, $n^{\circ}$ 54, Santa Fe, Argentina, Universidad Nacional del Litoral, enero-junio, 2018, pp. 15-41.

\section{Abstract}

This article analyses historian Tulio Halperin Donghi's contribution to our understanding of the Argentine history of the interwar years. It suggests that Halperin Donghi stresses the importance of the 1916-1943 period, and in particular the 1930s -the so called "década infame»- in order to explain the roots of the political instability of the second half of the XXth century. The paper highlights the differences between Halperin Donghi's approach to the study of the XIXth and XXth centuries, describes its most relevant arguments, and sets his contribution within the larger debate on the significance and most salient features of the interwar period.

\section{Descriptores - Describers}

Halperin Donghi / entreguerras / historia

Halperin Donghi / interwar period / History

Recibido: 25/06/2017

Aprobado: 28 / 02 / 2018 
¿De qué manera abordó Tulio Halperin Donghi la historia política de los años que corren entre el final del orden oligárquico y la aparición del peronismo? Este ensayo intenta responder a esta pregunta. Autor de prosa barroca y razonamientos complejos, que se despliegan en distintos planos de análisis y se ramifican en múltiples direcciones, es sabido que ya no la crítica sino la mera descripción de sus argumentos resulta una tarea compleja. Esta advertencia tiene relevancia para el tema que nos ocupa. Halperin Donghi se aproximó al estudio del tercio de siglo que separa el comienzo de las presidencias de Yrigoyen y de Perón a través de textos de muy distinta naturaleza -ensayos de intervención, artículos académicos, libros- que, por otra parte, vieron la luz en distintos momentos de su trayectoria y y de la historia del país. Ello introdujo novedades en la manera en que concibió los problemas de esa etapa, así como cambios de énfasis y perspectiva. Este artículo no aspira a reconstruir este recorrido en detalle. Se propone, en todo caso, señalar determinados rasgos de su enfoque y subrayar la relevancia de sus argumentos sobre la historia política del período (otras cuestiones, como su manera de encarar el debate intelectual, merecen un tratamiento específico) ${ }^{1}$. Aun cuando hace mención a distintos estudios, centra su atención en dos de ellos -Vida y muerte de la República verdadera (2000) y La República imposible (2004) - en los que, entrelazada con la narrativa política y el análisis de la discusión de ideas, Halperin Donghi reflexiona sobre la trayectoria democrática del país. En este sentido, hay que recordar que este historiador asigna especial relevancia a la década de 1930 en la definición de la problemática relación entre liberalismo y democracia. De allí que, subraya en su autobiografía Son memorias, en esos años «se esconde el nudo y la clave de la crónica crisis política» que signó al tormentoso siglo XX argentino (HALPERIN DONGHI, 2008: 305).

Situada entre el orden oligárquico y el peronismo, la etapa aquí considerada ha suscitado menos polémica que estos dos momentos que ocupan un lugar central en la disputa cívica y, en consecuencia, en la discusión entre especialistas. Los años I930 merecieron cierta atención, pero casi siempre en el marco de una preocupación más general por los orígenes del peronismo; el período radical, por su parte, se cuenta entre las etapas menos estudiadas de nuestro pasado. Esto sólo comenzó a cambiar entrada la década de 1980. Como parte de un fenómeno más amplio de profesionalización y expansión de los estudios históricos, también aumentó la

${ }^{1} \mathrm{Al}$ respecto, un breve pero agudo comentario en GORELIK (2013). 
producción sobre esos años. Al mismo tiempo, un clima de ideas marcado tanto por cierto enfriamiento de la cuestión peronista como por un mayor interés en la historia política, volvió más atractivo el estudio de esa etapa, banco de prueba de la república democrática. Importantes contribuciones surgieron en este marco ${ }^{2}$. Sin embargo, en comparación con otros períodos, aún permanece poco explorado. Leandro Gutiérrez y Luis Alberto Romero hicieron un influyente aporte a los estudios sobre esos años. En una serie de artículos reunidos en Sectores populares, cultura y política. Buenos Aires en la entreguerra, propusieron la idea de que los ańos transcurridos entre el fin de la Gran Guerra y el estallido de la Segunda Guerra Mundial deben ser concebidos como una unidad, sobre todo si se trata de captar el sentido de las grandes transformaciones sociales y de las orientaciones de la política popular: mejora gradual pero sustantiva de la condición de las mayorías, erosión de las contestatarias identidades populares y de clase forjadas en el cambio de siglo, atenuación del conflicto social, una política más inclusiva y reformista cuya expresión fue el ascenso socialista y sobre todo radical y, finalmente, retroceso de las opciones políticas y sindicales más extremas (GUTIERREZ y ROMERO, I995; también KORN y ROMERO, 2006). En particular, esta visión restó significación a 1930 -el año del golpe de Uriburu y de la Gran Depresión - como punto de inflexión en la historia de la primera mitad del siglo, en favor de una narrativa que privilegia la continuidad. En esas décadas, sugieren, se produjo una "callada transformación», que se desplegó poco a poco por debajo del ruido y la furia que impera en los escenarios de la gran política. Si bien esta visión suscitó objeciones de distinto tipo, ninguna de ellas impugnó frontalmente la nueva periodización, cuyo influjo puede observarse en estudios que comprenden desde la historia cultural a la del trabajo organizado ${ }^{3}$.

El éxito de esta perspectiva se advierte en el hecho de que el cronónimo «entreguerras» se naturalizó como forma de designar a esa etapa. Como sucede con

\footnotetext{
2 Véase, entre otros, ANSALDI, PUCCIARELLI y VILLARUEL (1993); DEVOTO y FERRARI (1994); FALCÓN 2000); DEVOTO (2002); de PRIVITELLIO (2003); MACOR y TCACH (2003); PERSELLO (2004); FERRARI (2008); FERNÁNDEZ IRUSTA (2009); HOROWITZ (2015); GERCHUNOFF (2016) y PRIVITELLIO y LÓPEZ (2015) ${ }^{3}$ Algunos ejemplos del influjo de esta perspectiva pueden verse en SARLO (1988) y CAMARERO (2007a). Aspectos específicos de esta manera de entender el período son discutidos en CAMARERO (2007b); CAIMARI (2012) y HORA (2015). En lo que refiere a la historia obrera, sin embargo, CAMARERO (2007b) ofrece una caracterización opuesta de esa etapa, que enfatiza no la disolución sino el fortalecimiento de una cultura proletaria. CAIMARI (2012) subraya la relevancia de la Gran Depresión en el plano social y HORA (2015) en el de la experiencia obrera.
} 
toda forma de periodización, también ésta se encuentra asociada a cierta imagen global de esos años. Expresiva de un humor que subraya el cambio gradual por sobre el giro brusco, y con frecuencia el signo reformista e inclusivo de esa etapa, su valor suele postularse ya no sólo para la ciudad de Buenos Aires (el laboratorio que sirvió inicialmente para forjar estos argumentos) sino para caracterizar la experiencia nacional en esas décadas.

Esta innovación contribuyó a colocar la historia de la democracia en una perspectiva de más largo plazo, que suavizó sus inflexiones y que incluso atenuó la relevancia del paso del orden oligárquico al democrático. En alguna medida, la política de la era oligárquica hoy es vista como más moderna, abierta e inclusiva y, en contraste, la del período radical, como menos renovada y menos transparente. Así, por ejemplo, un reciente trabajo de síntesis formulado en esta clave concluye que 1930 no significó «una ruptura sustancial» entre dos épocas históricas. La Argentina política a ambos lados de la fecha era «la misma», una «república reformista» nacida a comienzos de siglo, cuyos grupos dirigentes - que actuaban bajo el influjo de un proceso más general de civilización de las prácticas políticas y de fortalecimiento de las capacidades del Estado, cuyos orígenes se remontaban al siglo XIX-aun cuando explotaban los aspectos más corruptos del sistema político, también venían implementando reformas dirigidas a hacer más transparente y representativa la disputa cívica (en particular, en el plano de la práctica electoral) (de PRIVITELlio, 20I2a: 40).Lo nuevo, en todo caso, vino con el peronismo, y para explicarlo hay que prestar especial atención a la coyuntura de 1943-I946.

Para completar esta esquemática presentación hay que mencionar una serie de desarrollos que apuntan en otras direcciones. En el último cuarto de siglo ha cobrado fuerza un tipo de indagación sobre el campo del poder más atenta a la dimensión cultural de la política, a las peculiaridades locales y provinciales de la disputa ciudadana, a los problemas que plantea la representación, así como a la constitución de actores e identidades políticas, y a la dimensión de género. Las campañas electorales, las formas de movilización y los usos del espacio público, la prensa como actor de la vida cívica, el papel público de la mujer, el ascenso del catolicismo, son temas que concitan creciente atención ${ }^{4}$.

4 Véase, por ejemplo, PALERMO (1997 y 2013); ZANATTA (1999); KARUSH (2002); LIDA (2015); los trabajos reunidos en TATO y ROJKIND (2012); VALDEZ (2012) y GONZÁLEZ ALEMÁN (2014), entre muchos otros. 
Historiador de los grandes procesos que se despliegan en el centro de la escena política nacional, Halperin Donghi no se vio seducido por las novedades que ofrece esta agenda de trabajo, que no siempre se articula con las grandes visiones sobre el período. Tampoco abrazó la perspectiva que ve a la entreguerra como una unidad, y optó en cambio por enfatizar la importancia de 1916 y 1930, los hitos que dieron comienzo a la «República verdadera» y la «República imposible». En su visión, pues, la idea de entreguerra es problematizada. Antes de dirigir la atención hacia estas cuestiones, conviene dar un rodeo con el fin de explorar de qué modo encaró al estudio de esos años.

\section{EL ENFOQUE}

Es sabido que el siglo XIx fue el período que más interés despertó en Halperin Donghi. Y que el letrado, ese singular personaje que tanto le atrajo, constituyó un punto de observación a partir del cual intentó comprender los grandes problemas argentinos y latinoamericanos de los años que corren entre el ocaso del orden colonial y la emergencia de regímenes democráticos. En estudios como Una nación para el desierto argentino, por ejemplo, la reconstrucción del debate de ideas funciona como vía de entrada para entender aspectos centrales de la historia política de la etapa que va de la caída de Rosas al triunfo de Roca. Sin duda, Halperin Donghi produjo trabajos que fueron mucho más que una historia política de las elites letradas o que no se ajustaron a este molde -como Revolución y guerra o Guerra y finanzas-, pero estos actores fueron, con frecuencia, el mirador a partir del cual pensó problemas más amplios y construyó sus grandes argumentos (ALTAMIRANO, 1992 y 2016; HORA, 2005).

Figuras poderosas y polifacéticas -legisladores a la vez que literatos, políticos y también hombres de cultura-, los letrados ocupaban posiciones de autoridad en sociedades poco diversificadas como las latinoamericanas del siglo XIX, en las que el campo del poder y el mundo de las elites tienden a solaparse, y en las que las clases populares y los intereses organizados desempeñan un papel secundario en el drama histórico. De allí que, aun cuando Halperin Donghi se mostró atento a los factores que acotaban el poder de los letrados (HALPERIN DONGHI, I987a), estos sujetos le ofrecieran una valiosa vía de entrada para estudiar esas sociedades. Por obvias razones, el foco en este grupo no resulta tan productivo para reflexionar sobre el siglo xx. La constitución de campos de saber especializados, la creciente 
distancia entre alta política y cultura, y entre mundo del saber y mundo social, para no hablar del abismo entre el ámbito de la cultura y los poderes económicos y los intereses organizados hizo que, necesariamente, una mirada centrada en los herederos de los letrados decimonónicos dejara de ofrecer perspectivas válidas para la comprensión de las sociedades que cobraron forma tras la Gran Guerra.

En el siglo XX, los letrados perdieron relevancia en casi todos los planos de la vida social, y terminaron refugiados en las instituciones de la cultura y el sistema educativo. En «los tiempos que hemos vivido, los intelectuales nunca tuvieron ninguna influencia política» afirmó el historiador, que fue muy consciente de las implicancias de este retroceso (HALPERIN DONGHI, I994b: 45). Pues la creciente marginalidad de los descendientes de los letrados, así como la mayor abundancia de otro tipo de registros documentales, hizo que estos actores perdieran atractivo como mirador para pensar problemas que desbordan el campo de la cultura. La consecuencia es que los estudios de Halperin Donghi -cuyas principales preocupaciones, recordemos, siempre giraron en torno a los grandes procesos que dieron forma a las naciones latinoamericanas -sobre figuras del pensamiento del siglo XX son más escasos y en general de menor ambición analítica que sus trabajos sobre los letrados decimonónicos.

Las intervenciones de Halperin Donghi sobre cuestiones de relevancia pública, siempre perceptivas e informadas, lo muestran atento a los problemas del siglo xx. Sin embargo, sólo muy tardíamente publicó un volumen sobre los intelectuales que escribieron después de la Gran Guerra. Las tormentas del mundo en el Río de la Plata. Cómo pensaron su época los intelectuales del siglo XX, aparecido en 2015 , reúne ensayos sobre un conjunto de letrados ampliamente dominado por figuras argentinas, casi todos ellos escritos en la década y media previa a su fallecimiento (HALPERIN DONGHI, 20I5). Junto con los retratos más parciales y concisos ofrecidos en La Argentina y la tormenta del mundo. Ideas e ideologías entre 1930 y 1945 (2003) y en otros trabajos sobre el período ya mencionados, estos estudios muestran de qué modo reflexionó, hacia el final de su carrera, sobre el perfil de los hombres de cultura de su propio tiempo.

Recorrer las páginas de estos trabajos confirma que los hombres de ideas del siglo xx dejaron marcas superficiales sobre el mundo que les tocó en suerte. No sólo fueron menos influyentes que los letrados del siglo anterior sino que tuvieron una comprensión más limitada de su entorno. Y así como Halperin Donghi nunca se privó de señalar las cegueras y silencios de sus admirados letrados decimonónicos, 
también aquí se ocupa de señalar los aciertos de los intelectuales del siglo xx. La lucidez que por momentos reconoce en figuras como Ernesto Palacio -militante de la derecha católica y autoritaria- muestra que ese reconocimiento no se limita a los más afines al cuadrante donde anidan sus simpatías ideológicas, el del progresismo liberal (HALPERIN DONGHI, 2003: 95-98). Una evaluación global de los logros de estas figuras, sin embargo, muestra que sus triunfos fueron mucho más modestos e infrecuentes que sus extravíos y cegueras.

Esto vale para figuras como Eduardo Mallea («nadie hubiese encontrado en su torrencial producción literaria claves válidas para entender el siglo») y el prestigioso Leopoldo Lugones (que tuvo «un papel decididamente marginal» en la vida pública, reflejado en esa «implícita confesión de fracaso» que fue su suicidio en 1938) (HALPERIN DONGHI, 2OI5: I4, IO, 9) pero también para figuras por las que sentía más aprecio, como José Luis Romero. A diferencia de Mallea o Lugones, Romero no se enroló en las filas de los dolientes o de los pesimistas. Pero si su actitud ante la vida estuvo marcada por el optimismo, esta disposición no le permitió ver más lejos. El autor de Las ideas politicas en Argentina mantuvo a lo largo de casi toda su vida una injustificada confianza en que nuestro país carecía de grandes problemas. Sólo al final de sus días, transcurridos bajo el signo del terrorismo de Estado, comenzó a desengañarse de este dogma excesivamente simple. Pese a su talento como historiador, Romero no fue capaz de ver a la Argentina con ojos menos encandilados.

Esta evaluación desencantada de los logros del intelectual del siglo xx -en el plano del conocimiento y en el de la incidencia sobre el mundo- revela algo más que el pesimismo y la melancolía que fueron ganando a Halperin Donghi cuando se acercaba al final del camino. Y si ella se explica en parte por la marginación que resultó de la ya mencionada transformación estructural del lugar del intelectual en la sociedad moderna, se debe aún más a que el siglo xx resultó más difícil de interpretar que el anterior.

En la visión de Halperin Donghi, el siglo xIx estuvo marcado por lo que, evocando libremente a Eric Hobsbawm, podemos llamar «la doble revolución», esto es, el despliegue, firme y sostenido, de la civilización liberal y capitalista. Las demás fuerzas que le dieron forma a esa época dominada por muy extendidos ideales de progreso -el nacionalismo, la república constitucional, la democracia, los procesos de formación de Estados- contribuyeron a promover avances que, pese a la furia y el caos que siempre bullen en la superficie de la historia, apuntaban en una dirección 
convergente. Una vez que el período de inestabilidad que coincidió con las guerras napoleónicas llegó a su fin, la trayectoria de las sociedades nordatlánticas y, en su estela y con sus propios ritmos, de las latinoamericanas, siguió patrones comunes: expansión de la economía capitalista, progresos del liberalismo, fortalecimiento de los Estados, incremento del bienestar y la alfabetización de las mayorías, amplios consensos prácticos fundados sobre una valoración positiva de estos fenómenos. La expansión colonial tuvo consecuencias dramáticas sobre muchas poblaciones de África y Asia -a las que cubrió de violencia y muerte- pero se desplegó sin que el espacio a partir del cual reflexionaban figuras como Mill, Marx o Weber se viera trastocado. Y ello hizo más sencillo interpretar, a ambos lados del Atlántico, en qué dirección marchaba el mundo. Por todo ello, y al margen de las dificultades que siempre supone la profecía de corto plazo, a los letrados decimonónicos -y en particular a los que escribieron en la segunda mitad de ese siglo, cuando los procesos mencionados se consolidaron-, les tocó un panorama más sencillo de descifrar.

Los intelectuales del siglo xx enfrentaron un escenario más complejo. Ese período estuvo marcado, para decirlo con las palabras de Halperin Donghi, por grandes tormentas y giros abruptos y desconcertantes. Enigmático y cambiante, no fue fácil vislumbrar sus tendencias de largo plazo. Contemplado con la vista puesta en los sucesos de Europa occidental y América Latina, la sucesión de nuevos cuadros fue vertiginosa. La centuria se inició con una gran carnicería en la que naufragó parte considerable del legado político e ideológico del siglo xIX, y que en las lejanas periferias del este europeo abrió paso al comunismo. La década de I920 pareció sentar las bases de un orden más progresista y democrático, pero este remató en una crisis económica de hondura sin precedentes y en la consolidación de regímenes ambiciosos y brutales. Las victorias del fascismo y el nazismo fueron brillantes pero efímeras. La democracia liberal, que en la década de 1930 parecía muerta, revivió tras una guerra aún más mortífera que la de 19I4-I9I8. Su renacimiento se apoyó sobre un capitalismo que, domesticado por el Estado de bienestar, por primera vez exhibió un rostro verdaderamente inclusivo.

Pronto, sin embargo, en la Europa meridional y sobre todo en América Latina, la revolución y el socialismo parecieron dueños del futuro. Pero en la década de I970 su marcha fue interrumpida por sangre y violencia. Poco después retornó la democracia, aunque maridada con un capitalismo cada vez más desigual y excluyente. Antes de que el siglo se cerrara, el derrumbe del mundo soviético y la adopción de la economía de mercado por la China comunista hicieron que la 
victoria del capital alcanzase una dimensión planetaria. Estos fenómenos también se acompañaron de un desplazamiento del eje de poder hacia Oriente que -si bien juzgado con sospecha por los que tienen sus ojos fijos en el deterioro de los Estados de bienestar occidentales- trajo una mejora sustantiva de las condiciones de vida de las mayorías en las regiones más pobladas del planeta. El siglo Xxi también se abrió con sorpresas, como las guerras de religión.

En este mundo de equilibrios efímeros, los intelectuales que se mantuvieron fieles a los ideales y creencias heredados del siglo XIX, o que los trocaron por otras formas más modernas del optimismo, sólo pudieron sostener su fe a costa de una mutilación de su voluntad de comprender. Quienes se creyeron capaces de interpretar su tiempo se expusieron a ser desmentidos en el curso de pocos años. De allí que esta época no se prestó para la consagración de pensadores de ambiciones olímpicas como Durkheim, Marx o Weber. Observando el problema en escala local, no extrańa que careciera de figuras capaces de ofrecer intuiciones tan certeras como las que Halperin Donghi creyó identificar en figuras de la etapa anterior como Josef de San Alberto o Juan Bautista Alberdi, para no hablar de sus admirados Mitre y Sarmiento.

Para cerrar este bosquejo es preciso referirse a dos personajes disonantes que Halperin Donghi se propuso destacar: Raúl Prebisch y Fernando Henrique Cardoso. En un ensayo de 2008, Halperin Donghi presentó a Prebisch como quizás el único intelectual latinoamericano que estuvo a la altura de los grandes letrados del siglo xix. Este elogio se justifica porque el creador de la Comisión Económica Para América Latina (CEPAL) fue de los pocos que entendió los grandes problemas de su era y, todavía más importante, que fue capaz de incidir en su curso. El historiador lo describió como "uno de los artífices de este mundo del tercer milenio» (HALPERIN DONGHI, 20I5: I5). Si Prebisch merece un lugar en la historia grande de América Latina no es por su contribución propiamente intelectual, sino por su capacidad para articular ciertas ideas con un programa de acción que, para llevarlo a la práctica, dependía de destrezas que no eran sólo ni centralmente letradas. Halperin Donghi alabó la destreza con que Prebisch impuso la idea de que el Estado (primero argentino, luego latinoamericano) debía incrementar sus capacidades técnicas dirigidas a promover el crecimiento y la diversificación de la estructura productiva y, sobre todo, para redefinir el patrón de inserción internacional de las economías latinoamericanas. Pero celebró aún más su talento para traducir estos objetivos en un proyecto institucional tan sólido como la CEPAL, que por un cuarto de siglo se erigió en motor del programa desarrollista en América Latina. 
Esta visión de lo que significa ser un gran intelectual en nuestros tiempos -en la que parece colarse cierta añoranza por la polifacética figura del letrado decimonónico- también ofrece la clave de su admiración por Cardoso, por cuyo trabajo propiamente académico , por cierto, sintió escaso aprecio (HALPERIN DONGHI, 2015: I5). El gran mérito de este profesor devenido en presidente de la nación más importante de América del Sur consistió en sostener el proyecto de actualización del legado de la CEPAL, desenvuelto en medio de las hostiles circunstancias que siguieron a la crisis de la deuda y la «década perdida», cuando América Latina parecía rendirse ante el embate de las fuerzas del capitalismo globalizado.

En síntesis, el modo en que Halperin Donghi concibe el contexto y las circunstancias en que se desenvolvió el trabajo intelectual en los tiempos que le tocó vivir, así como el tipo de destrezas que elogió y los logros que identificó, ayudan a entender por qué no reconoció grandes deudas con los analistas del siglo xx, ni les asignó tanta relevancia como intérpretes de su tiempo. En sus trabajos dedicados a esta centuria no encontró la guía de ningún equivalente a lo que Mitre o Sarmiento, o incluso Marx o Weber, significaron para definir su visión del siglo previo. En ellos el lector buscará en vano la estrecha identificación entre el punto de vista del actor y el del historiador que constituye uno de las recursos retóricos más característicos de estudios como Una nación para el desierto argentino. La contracara de este cuadro es una estrategia analítica menos respetuosa de las ideas de los intelectuales y más centrada en actores propiamente políticos, a punto tal que uno de sus libros que aborda el debate de ideas, La República imposible, ha sido calificado «como el ejercicio de histoire événementielle más excepcional que se haya escrito entre nosotros» (GORELIK, 2OI3: 7). Con frecuencia, esas figuras más planas que son los intelectuales del siglo xx cumplen la función de testigos o de protagonistas de dramas cuyos libretos no siempre alcanzan a comprender. Con menor asiduidad les es asignado el papel del analista o del intérprete, y muy rara vez el del gran pensador. Y el hecho de que un artista de la pluma como Borges, evocado de manera repetida en sus escritos sobre el siglo xx, le sirva como un inspirador de fórmulas para pensar los problemas de esta centuria es bien revelador de esta situación. 


\section{LOS ARGUMENTOS}

Al observar en conjunto la producción de Halperin Donghi sobre el siglo xx se advierte que el período de entreguerras fue la etapa de nuestro pasado a la que más atención dedicó. Lo hizo de dos maneras. En el decenio que siguió a la caída del peronismo escribió una serie de ensayos sobre lo que entonces era el pasado inmediato que comprendían este período. Entre ellos se cuenta «El frondizismo en el espejo de la historia» (I958), publicado en Contorno, «Crónica de treinta años» (I96I), aparecido en el célebre volumen con que la revista Sur conmemoró sus tres décadas de vida y Argentina en el callejón (1964), que vio la luz en la editorial montevideana Arca. Tres décadas más tarde, cuando este período se había hundido en el pasado, Halperin Donghi volvió a interrogarlo y entonces produjo textos más específicamente centrados en la política y el debate de ideas. A esta etapa corresponden Vida y muerte de la República verdadera (2000) y La República imposible (2004) y en un subproducto de esa exploración, La Argentina y la tormenta del mundo (2003).

Reflexiones de naturaleza más ensayística que académica, el primer ciclo de escritos mencionado fue concebido cuando sus esfuerzos historiográficos más sistemáticos estaban orientados al análisis de la crisis del orden colonial y la formación de la república independiente, en un ciclo que va de Tradición politica española e ideología revolucionaria de Mayo (196I) a Revolución y Guerra (1972). Halperin Donghi los escribió al ritmo de una historia en curso, y sobre ellos pesó tanto su condición de protagonista como de observador. Vistos a la distancia, pues, revelan la perspectiva de un analista lúcido pero a la vez inmerso en las pasiones de su tiempo. Su mirada no pudo evitar los sesgos de su mundo social (el segmento más ilustrado de las clases medias progresistas) y del momento de producción (el período de inestabilidad posterior al derrocamiento del peronismo).

¿Qué nos dicen estos textos? Algunos autores han visto en estos trabajos un tratamiento original del período que va de Uriburu a Castillo (altamirano, 2OI2: I3-I4). No obstante, el joven Halperin Donghi encuadró su narrativa -sin duda sofisticada- en una visión convencional de los años 1930, que incluso refleja cierto denuncialismo de inspiración contornista. Reconstitución del dominio oligárquico, involución económica y retroceso social aparecen en esos textos como claves de la década. Argentina en el callejón se refiere a ese período apelando a la expresión de «restauración conservadora», y sugiere que un rasgo singular de ese período fue «la debilidad de todas las expresiones políticas que no son expresión de las clases privilegiadas tradicionales» (HALPERIN DONGHI, [I964] I994a: I2I). En esa sociedad 
pasiva y reprimida, el grupo gobernante creó instituciones y puso en marcha iniciativas que le dieron un cariz más moderno y transformador a la gestión económica. Pero lo hizo para proteger los intereses de la elite terrateniente, y en desmedro de otros sectores subordinados de las clases propietarias (ganaderos perjudicados por los acuerdos comerciales con Gran Bretańa, entre otros) y de la sociedad en su conjunto. La vida pública, sugiere, no fue sólo fraude y retroceso. Pero nada impidió que el talentoso elenco de funcionarios que pasó a dirigir la economía colocara sus destrezas al servicio de un orden excluyente, vuelto sobre el pasado.

De hecho, en Argentina en el callejón no hay mayores referencias al proceso de diversificación productiva acontecido tras la depresión, a punto tal que el salto adelante de la producción manufacturera y la creciente gravitación del trabajo organizado son entendidos como el producto del aislamiento nacido tras el estallido de la Segunda Guerra Mundial. En rigor, una imagen alternativa sobre los años 1930, que enfatiza no sólo las innovaciones verificadas en el plano estatal sino también en el societal (crecimiento de la producción para el mercado interno, expansión del proletariado fabril) sólo se abriría camino desde fines de la década de 1960. Y el impulso para esta renovación de la imagen de la «década infame» no provendría de los cultores de la historia sino de las nuevas ciencias sociales y, en particular, del debate sociológico sobre los orígenes del peronismo. Fue esta discusión la que definió al ciclo de transformaciones inaugurado hacia 1932-1933 no tanto como la contracara sino más bien como la condición de posibilidad y la antesala del nuevo orden surgido en $1945-1946^{5}$.

Pero si el retrato de la década de 1930 que nos ofrece este Halperin Donghi es erudito y sofisticado, aunque en aspectos sustanciales todavía convencional, lo que sí es más original y en definitiva más productiva es su visión de la sociedad creada en el medio siglo previo bajo el impulso de la expansión exportadora y la inmigración europea. En Argentina en el callejón, la trayectoria histórica del país es situada en el contexto de un relato de largo plazo que subraya la profundidad del proceso de cambio social forjado al calor del patrón de crecimiento impulsado por las exportaciones agrarias. Y aun cuando ese patrón es pensado como ya agotado, Halperin Donghi toma distancia de las interpretaciones que enfatizaban el carácter excluyente del orden social construido bajo la inspiración oligárquica. El énfasis en

\footnotetext{
${ }^{5}$ Los principales hitos de esta discusión son reconstruidos en TORRE (1989) y MACOR y TCACH (2003).
} 
la formación de una sociedad compleja y dinámica nos reenvía a su propia biografía: esa historia de progreso de dos familias de inmigrantes que más tarde relataría en Son memorias. Y un punto que le interesa subrayar es el peso social y cultural adquirido por las clases medias conforme esa nueva sociedad iba tomando cuerpo.

Esa Argentina transformada por los logros sociales del proyecto liberal puesto en marcha en tiempos de Sarmiento, Mitre y Roca es el escenario en el que Halperin Donghi sitúa el drama que sale a la luz con el golpe de Estado de 1930. Y en su visión ese problema puede ser sintetizado como la dificultad para consagrar una fórmula política capaz de encauzar y procesar la vasta transformación social que dio vida a esa sociedad diversificada y compleja cuyo emergente más poderoso es el ascenso de los sectores intermedios.

La relación entre democratización y clase media, sin embargo, no es concebida con arreglo al paradigma analítico entonces en boga que concebía al radicalismo como el partido que representaba, expresaba o se identificaba con este grupo cuya identidad en el plano social y cultural, mucho más que en el político, se estaba perfilando con nitidez en esas décadas. En la visión de Halperin Donghi, esa relación está recorrida por tensiones. Pues si su manera de entender el proceso de cambio social en la era oligárquica coincide en muchos puntos con la preferida por analistas como Gino Germani, que también había enfatizado la importancia de los fenómenos de diversificación social desplegados en el primer tercio de siglo, su visión de los problemas políticos de la era radical avanza por otro carril.

De hecho, apelando a un argumento de resonancias antigermanianas, Argentina en el callejón sugiere que el orden democrático consagrado en I9I6 y, en particular, el giro plebeyo que produjo la conquista yrigoyenista de la presidencia enı928, no sólo desplazó a una posición políticamente marginal a la elite tradicional sino también a la clase media. Aunque todas las consecuencias de la reforma de 1912/1916 tardaron en manifestarse, el incremento de la participación tuvo un impacto profundo sobre el orden político. La consecuencia fue que las clases medias, el grupo más dinámico y expansivo de ese país en transformación, no lograron alcanzar una gravitación política equivalente a su creciente peso social y cultural. De allí que el ascenso radical dejó por herencia no sólo «una aristocracia terrateniente despechada» sino también, y más importante, a «una clase media a la que la democracia de sufragio universal parece privar del papel políticamente hegemónico que esperaba del futuro» (HALPERIN DONGHI,[I964] I994a: IO3). Cambio social y cambio político no sólo se desplegaron de manera asincrónica sino también conflictiva. 
La crisis inaugurada en 1930 surge entonces de tensiones propiamente políticas, pero en cuya formulación el patrón de incorporación de nuevos grupos sociales a la vida pública ocupa un lugar relevante. Si bien la narración concentra su atención en las elites dirigentes y en los principales actores de la vida pública, en el plano analítico nos ofrece una explicación que, vía las reacciones suscitadas por el "populismo" radical, asigna un papel mediado pero decisivo a los determinantes de clase. Aun cuando en trabajos posteriores el peso analítico de esta dimensión -y más en general de las determinaciones económico-sociales- se verá acotado, este argumento volverá a reaparecer (se observa, por ejemplo, en La larga agonía de la Argentina peronista [1994], donde el problema del lugar político de las clases medias ayuda a explicar la inestabilidad de la segunda mitad del siglo xx).

En Argentina en el callejón, el factor clase se encuentra mediado por otras instancias analíticas, comenzando por el hecho de que el campo político es concebido como una arena en la que inciden múltiples actores, cuya interacción vuelve contingente el resultado del proceso político. Al mismo tiempo, Halperin Donghi sitúa su historia en el marco de las singularidades de la economía exportadora, en la que subraya las fragilidades de ese orden con un énfasis que, pasado el clima de época desarrollista en el que este trabajo fue concebido, resulta excesivo para nuestra sensibilidad contemporánea. Atento al influjo del escenario internacional, también señala que la erosión del liberalismo constitucional en los países del Atlántico norte incidió sobre la crisis política argentina. Sin embargo, la clave de la «guerra civil larvada» (una fórmula que le sirve para enfatizar el carácter enconado de los enfrentamientos, pero que no volverá a emplear de manera sistemática más tarde) que se abre en 1930 no debe localizarse en el plano de las tensiones económicas o las disputas sociales, y mucho menos en el de las luchas ideológicas. El problema de fondo radica en la imposibilidad de forjar una fórmula capaz de integrar políticamente a los grupos medios crecidos al calor del proceso de diversificación social impulsado por el auge exportador.

De este modo, 1930 marca el comienzo de una crisis de la república constitucional subtendida por la incapacidad de reconciliar los intereses y demandas de los viejos y los nuevos actores políticos que, cuando Halperin Donghi la contemplaba a comienzos de 1960, no había alcanzado su punto de llegada. Y fueron precisamente los avatares de los tres principales intentos de cerrar esta crisis (a los que denomina la república oligárquica restaurada, el peronismo, la semidemocracia posperonista) los que concentran su atención en todos esos textos. 
Esta no es la ocasión indicada para explorar los detalles de esa narrativa rica en intuiciones. Sin embargo, vale la pena mencionar dos fructíferas líneas de indagación que se desprenden de ella. La primera se refiere a la distancia entre las percepciones de Perón y de la elite empresaria en torno a la cuestión de la intensidad y el grado de radicalización de la movilización obrera de comienzos de la década de 1940. Este argumento fue retomado en trabajos posteriores (como La vieja guardia sindicaly Perón, de Juan Carlos Torre) para explicar los desencuentros entre estos dos actores claves del drama de 1945 y su peculiar desenlace. El otro se refiere a la toma de distancia respecto de las interpretaciones en las que la crisis política nacional es vista como un eco de las disputas políticas e ideológicas que entonces dividían al Viejo Mundo o, alternativamente, en el que el arsenal ideológico acuñado en Europa resultaba fundamental para explicar el comportamiento de los actores políticos locales. Ello se refleja, por ejemplo, en la escasa relevancia asignada a la derecha nacionalista y en el rechazo a interpretar el comportamiento de Perón a la luz de su supuesta identificación con el ideario fascista. Por el contrario, se subrayan los rasgos más idiosincráticos del universo de ideas políticas argentino. Y con ello se abre camino una reflexión dirigida a poner de relieve la importancia de las tradiciones políticas nacionales para analizar tanto la acción como la dimensión proyectual de la política.

En todos estos ensayos, Halperin Donghi hace suyo el argumento de que el gobierno de Perón sólo introdujo retoques menores a la arquitectura del país. Su política económica, sostenía entonces, fue «sólo parcialmente innovadora y aún más escasamente previsora» (HALPERIN DONGHI, [1964] 1994a: 156). El peronismo fue, ante todo, un programa de nacionalización de la economía y de distribución de los recursos que sólo podía sobrevivir en tiempos de holgura fiscal y prosperidad exportadora. Sus grandes innovaciones, agrega, no sobrevivieron a su caída. Creado desde arriba, moderado en su programa de cambio social en parte por la pasividad de sus apoyos populares, no dejó sino una herencia modesta. Sus legados más perdurables fueron la consolidación de la presencia industrial (un proceso de todas maneras ya comenzado durante la guerra, antes de la irrupción de Perón, y que también se observaba en otros países de América Latina) y la erosión de ciertos «valores tradicionales», a los que Halperin Donghi entonces no atribuía ninguna dimensión de clase. Concebido como apenas un desvío en la trayectoria histórica nacional, el peronismo no tenía futuro.

Esta visión debe mucho a la sociabilidad letrada (y por ello de impronta antiperonista) en la que Halperin Donghi forjó su primera mirada sobre el país. 
A comienzos de la década de 1960, sin embargo, el argumento de que Perón y el justicialismo eran puro pasado se hallaba extendida más allá de esos círculos. De hecho, todavía resultaba verosímil para muchos intérpretes y actores de la vida pública en tiempos de Frondizi e Illia, y para ello no hay más que evocar la discusión de inspiración germaniana sobre el camino que tomarían esas «masas en disponibilidad» que habían sido la base electoral del régimen y que desde 1955 parecían haber perdido no sólo su caudillo sino también su norte o, unos años más tarde, el renacimiento del proyecto laborista acaudillado por figuras como Vandor.

El paso del tiempo desmintió estas creencias y puso de relieve el arraigo del peronismo en la cultura popular y en la vida pública. De allí que, tres décadas más tarde, cuando Halperin Donghi volvió de manera más sistemática al estudio de la primera mitad del siglo xx, su manera de entender el problema sufrió grandes cambios. En La larga agonía de la Argentina peronista, aparecido cuando un peronismo muy renovado ocupaba por tercera vez la Casa Rosada, lo describió como al actor político que desencadenó un profundo proceso de transformación social e institucional que, en apenas un trienio (I945-1948) dio forma a un cuadro de relaciones sociales y económicas enteramente nuevo, signado por la gravitación del trabajo organizado. Para entonces Halperin Donghi no dudaba de que, si el indicador para juzgar la relevancia de un proceso de cambio es la alteración del lugar de los trabajadores en la comunidad nacional, la fuerza nacida en 1945 había transformado la sociedad de manera más profunda y perdurable que muchos Estados del siglo xx que se proclamaban o se habían proclamado revolucionarios. Lejos de quedar confinada a los discursos en los que los grupos dirigentes se celebran a sí mismos, la drástica modificación de las jerarquías sociales y las relaciones de poder vivida en la era peronista afectó todas las relaciones sociales, a punto tal que para palparla «bastaba caminar por la calles o subirse a un tranvía» (HALPERIN DONGHI I994C: 26).

Como se ve, en este punto su manera de concebir al peronismo cambió diametralmente. Si en la década de 1960 creía, como entonces era frecuente entre la intelectualidad progresista o de izquierda, que la fuerza creada por Perón carecía de vocación revolucionaria, ahora la juzgaba más innovadora (sobre todo en el plano de la alteración de las relaciones de clase) no sólo que experimentos como la Revolución Mexicana e incluso que el propio fascismo que antes había sido ungido como la vara con la cual determinar qué es una revolución de derechas. $\mathrm{Y}$ hay que conceder que el abrupto cambio en el patrón distributivo consagrado en 1946 constituye un fenómeno inusual; aun cuando la organización capitalis- 
ta de la economía no fue amenazada, el incremento del salario y la mejora del bienestar popular alcanzados en apenas tres años invitan a preguntarse si muchos trabajadores de las sociedades comunistas nacidas en esos mismos ańos, en caso de haber tenido opción, hubieran preferido vivir en la Argentina de Perón. Y este paralelo permite situar la idea de «revolución peronista» en una perspectiva más amplia: esta manera de reevaluar el legado del justicialismo tuvo lugar bajo el impacto del derrumbe del denominado socialismo real, ese gran cataclismo que, parece sugerir Halperin Donghi, obliga a revisar (y en gran medida a devaluar) el significado histórico del concepto de revolución.

Con todo, su explicación del ascenso de Perón retomó líneas de análisis ya presentes en sus textos de la década de 1960. Aunque la reconstrucción del fenómeno atiende a múltiples dimensiones, un aspecto que enfatizó se refiere a la capacidad de innovación política de la nueva elite estatal llegada al poder en I943. Desde su punto de vista, la orientación política de Perón se definió en una coyuntura específica, caracterizada por profundas tensiones entre las elites propietarias y los jerarcas de la Revolución de Junio, producto a su vez de distintos diagnósticos sobre los peligros que suponía la movilización obrera. La hostilidad del empresariado terminó empujando al secretario de Trabajo y Previsión a acentuar los rasgos obreristas de su proyecto de poder más lejos de lo que este hubiese deseado. Es decir, Halperin Donghi puso el foco de atención en las disputas y debates entre los grupos dirigentes más que en el plano de la política de masas y, en este punto, su manera de abordar el problema revela claras continuidades con sus trabajos sobre etapas anteriores.

Sin embargo, planteó de otro modo la relación del peronismo con un pasado que por entonces ya conocía no sólo como un testigo que observa o rememora sino también como un analista al que el alejamiento de su objeto le permite advertir otro paisaje. Esta distancia no nació sólo del hecho de que el transcurso del tiempo fue hundiendo a la década de 1940 en el terreno de la historia. Surgió, también, de la convicción de que en el período de entreguerras no sólo se jugó la suerte de la primera democracia argentina sino también de todo el proceso de construcción institucional del que la república democrática formaba parte. Vida y muerte de la República verdadera, que analiza el fin del orden oligárquico y el período de gobiernos radicales de 1916-1930, y La República imposible, enfocado en la etapa 1930-1945, exploran estas cuestiones. En estos trabajos, el debate de ideas se despliega sobre el fondo de una minuciosa y sofisticada reconstrucción de la historia política que, con frecuencia, ocupa el primer plano de la indagación. 
Vida y muerte de la República verdadera analiza la conquista del Estado por parte del radicalismo de Yrigoyen y las respuestas que ello suscitó en las elites conservadoras y las demás franjas de la oposición. Explora también un amplio conjunto de cuestiones que animan el debate público: la reforma universitaria, la guerra europea, la revolución rusa, el ascenso del fascismo, las transformaciones del sindicalismo y el catolicismo, el debate político y parlamentario. Historia de la alta política, el relato no se enfoca en la política popular y tampoco se interroga por la manera en que los hombres del común vivieron esa experiencia. Pero la periodización elegida y las referencias a las reacciones que la democratización suscitó en los grupos dirigentes nos muestran el profundo impacto de 1916 sobre la vida pública (y ello vuelve a confirmar la necesidad de comprender mejor este proceso, tan crucial como poco investigado).

A diferencia de las visiones que subrayan las continuidades con el orden político oligárquico -ya sea por la pervivencia de redes de autoridad y formas políticas clientelistas o, alternativamente, por la persistencia de prácticas de manipulación del sufragio-, Halperin Donghi enfatiza los aspectos novedosos del escenario democrático ${ }^{6}$. Factores tales como el cambio de escala en la competencia electoral, la incertidumbre sobre sus resultados, la mayor autonomía de los votantes, la forja de sólidas identidades políticas en las clases populares, la emergencia de nuevos actores en la vida pública, el cambio en las estrategias proselitistas y la renovación de los grupos dirigentes, dibujan un panorama bien distinto al prevaleciente hasta I9I2-I916.

Todo ello aparece subtendido por el gran tema del encuentro entre liberalismo y democracia. Tras un exhaustivo análisis de toda una serie de procesos y actores que dan cuenta de la notable expansión del universo de ideas -que va desde el ascenso de la izquierda que se inspira en la Revolución Rusa a la consolidación de una nueva derecha antiliberal- Halperin Donghi subraya la persistencia de los ideales nacidos durante el período de la Organización Nacional. Pese a muchas novedades y movimientos en los márgenes, sugiere Vida y muerte, la vida pública continuó girando en torno a una única tradición política, el liberalismo constitucional, y a un único ideal, la república democrática.

El amplio consenso en torno a la legitimidad de este modo de articulación entre sociedad y Estado también fue señalada por Fernando Devoto en un estudio publicado por esos mismos ańos (Devoto, 2002). Pero mientras Devoto se

6 Para un ejemplo de la primera opción, FERRARI (1996); de la segunda, de PRIVITELLIO (2012b). 
enfoca en las limitaciones de la derecha nacionalista y autoritaria para ofrecer una alternativa consistente y atractiva al liberalismo y la democracia representativa, Halperin Donghi también explora las singularidades de esta cultura política. Amén de su frecuentemente mencionada condición de liberalismo de gobierno antes que de oposición (y, por tanto, más sensible al problema del orden que al de la libertad), otros dos rasgos, ambos heredados del siglo previo, caracterizan a esta cultura política: su inspiración progresista y su hostilidad al pluralismo político. Este último punto le sirve de guía para introducirse en el análisis de los conflictos entre gobierno y oposición, y para interpretar al principal personaje de ese drama, el «enigma Yrigoyen», quien veía a su partido como la única fuerza legítima de la vida pública y cuyo triunfo, por tanto, concebía como prueba de la victoria del ideal democrático.

En respuesta al ascenso radical y el incremento de la participación popular, el principio democrático, que desde Caseros siempre había funcionado como horizonte de la vida pública, comenzó a colisionar con otro ideal que valoraba la competencia administrativa y se apoyaba en el principio del gobierno de los mejores. Esta disputa, sin embargo, opacó pero no eclipsó al ideal democrático en tanto horizonte de referencia para los sectores predominantes de la vida cívica. Así, pues, el conflicto de legitimidades que tensionó la era radical se desplegó en el seno de una visión encuadrada por ese liberalismo progresista en el que la elite dirigente fundaba su derecho a gobernar y que a la vez la dotaba de un mapa con el que orientar sus iniciativas de reforma.

Estos problemas reaparecen en La República imposible, consagrado a la década de 1930. La relevancia de este período no se asocia, como propusieron los estudios elaborados en las décadas de 1970 y 1980 que pretendían comprender los orígenes del peronismo en clave económico-social, al impacto de la depresión sobre el perfil productivo del país (pérdida de dinamismo del sector exportador, crecimiento industrial impulsado por la sustitución de importaciones, etc.) y su estructura de clases (incremento del peso del trabajo industrial y en menor medida del empresariado fabril) y al marco político en el que se daban estos procesos (un orden autoritario al servicio de los grupos propietarios). Halperin Donghi hace suya la visión que enfatiza que, tras el derrumbe de 1929-1932, la recuperación económica no sólo fue veloz sino también en gran medida liderada por el reverdecimiento del sector exportador. De allí que esas transformaciones socio-económicas aparezcan en La República imposible como menos significativas de lo que solía afirmarse hace 
un cuarto de siglo. Desplaza así hacia el fondo del escenario a los conflictos y tensiones sociales (incluyendo su dimensión de clase) para enfatizar que los principales dilemas del período giran en torno a problemas específicamente políticos, entre las que por su importancia sobresale el referido a cómo y por qué la dirigencia conservadora se orientó por el camino del fraude y la falsificación institucional. Organizado en torno a esta cuestión, La República imposible constituye el primer relato consistente sobre la trayectoria y los dilemas políticos de la «década infame».

Habitualmente concebido como un derivado de la naturaleza antidemocrática de la elite conservadora y/o del impacto del avance de las ideas autoritarias de nuevo cuńo forjadas en la Europa de la entreguerra, el fraude ha sido poco problematizado. Con frecuencia, la impugnación se impuso a la comprensión. $L a$ República imposible desnaturaliza el fenómeno y se interroga por su historia y las razones que lo hicieron posible. Enfatiza las diferencias cualitativas con formas anteriores de la prepotencia electoral y, a renglón seguido, explica su trayectoria y la del ilegítimo régimen que marcó la política de esa década. Lo hace a través de una exploración que se despliega en tres planos.

Una primera dimensión del problema del fraude refiere a las ideas que animaban a los grupos dirigentes que ayuda a comprender cómo estos actores lo justificaban ante sus propios ojos. En este punto, el historiador enfatiza la vitalidad del ideario liberal heredado del siglo xIx, que imaginaba a la democracia no como un mero mecanismo para elegir autoridades sino como un proyecto a realizar, que requiere una ciudadanía educada. En segundo lugar, presta atención a las constricciones prácticas que operaban sobre los gobernantes. Aquí su atención está enfocada en el dilema que la persistencia del poder electoral radical le planteaba a la heterogénea constelación política en el poder, que atiende a las disputas por la preeminencia política entre distintas facciones conservadoras y antipersonalistas. Finalmente, sitúa estos problemas en el marco de una detallada reconstrucción de los giros y contramarchas de la vida política que nos recuerda que, como toda política, la del fraude tuvo actores y una historia de naturaleza contingente.

Al cabo de este recorrido, la aberrante solución que se fue abriendo camino hasta teñir de ilegitimidad toda la vida pública nacional emerge, más que como la expresión del cinismo o el autoritarismo de los conservadores, como un drama de naturaleza compleja que, entre otras cosas, pone de relieve la importancia que la dimensión proyectual de la política todavía conservaba para la elite gobernante. Imposibilitado de negar -y por ende obligado a traicionar- a la democracia re- 
presentativa a la que seguía concibiendo como el único horizonte aceptable para esa nación en construcción, esa elite se fue encerrando en un callejón sin salida.

Halperin Donghi nos ofrecen un relato que, sensible a los cambios y continuidades en la vida pública del período de entreguerras, contribuye a situar al nuevo escenario cristalizado en 1945-1946 en una perspectiva de largo plazo. Tanto es así que, en distintos ensayos escritos de modo paralelo a La República imposible, Halperin Donghi enfatizó una serie de puntos de continuidad que, en el plano de los modos de hacer política, en el de la concepción sobre el papel del Estado, y en el de los valores que ofrecían el horizonte hacia el que debía encaminarse la Argentina, unen al peronismo con experiencias políticas anteriores. Así, por ejemplo, subrayó que, sin siquiera advertirlo, Perón era tributario de formas de representación del liderazgo político que ya eran visibles en los años de apogeo liberal (HALPERIN DONGHI, 1993). El rechazo del peronismo al pluralismo político, continúa el historiador, también hundía sus raíces en formas de entender el ejercicio del poder que unían a Rosas con Mitre y Roca, y a estos con Justo y Fresco (halperin Donghi, 1997). Mucho antes que Perón, ya los liberales del siglo XIX habían concebido al Estado como un agente de cambio capaz de orientar la sociedad y moldearla desde la cumbre (HALPERIN DONGHI, I992). Finalmente, también subrayó que el reformismo social ya ocupaba un lugar gravitante entre las ideas de la clase dirigente liberal de las primeras décadas del siglo. Desde entonces la preocupación por la justicia social formó parte de los denominadores comunes de un consenso progresista que comprendía desde el socialismo hasta los sectores más esclarecidos del conservadurismo.

De este recorrido se sigue que, si Halperin Donghi está en lo cierto, el principal fenómeno político de la segunda mitad del siglo xx no puede ser concebido como una ruptura radical sino como una deriva posible dentro de los modos de hacer y entender la política vigente en 1943/1945. En los últimos años, por otra parte, se ha vuelto frecuente enfatizar las continuidades entre el peronismo y quienes lo precedieron (PALACio, 20IO). Todos estos lazos con el pasado, sin embargo, vuelven más intrigante el rechazo frontal del peronismo a concebirse como un heredero -así sea bajo la forma de una fuerza profundamente crítica y renovadorade las experiencias políticas previas (esto es, de alguna de las vertientes del gran río liberal que constituía la única tradición política de peso en el país). Pues en esa Argentina que, desde el punto de vista socioeconómico, no nació de nuevo en la década de 1930, y a pesar de todas las continuidades señaladas en el párrafo 
anterior, y a otras que podrían mencionarse, el peronismo le dio la espalda al gran cuerpo de ideas que hasta entonces había servido de cauce a la política nacional. Y a ello hay que agregar que, aún si esta iniciativa provino de Perón, la vocación parricida del nuevo líder encontró una amplia aceptación entre sus votantes populares, que parecieron no sentir nostalgia alguna por el desplazamiento de la tradición política dentro de la cual habían sido interpelados por más de medio siglo. Y, sugiere Halperin Donghi, si hay un momento particular que ayuda a entender esta abrupta mutación, así como los amplios apoyos populares que concitó, no puede ser otro que el que corre entre Uriburu y Castillo. Más que cualquier otro hito, lo que entonces sucedió es clave para entender por qué el peronismo se constituyó como una fuerza que no reconocía más relación con el pasado que su voluntad de abolirlo, y por qué se definió en ruptura con todas las tradiciones previas (HALPERIN DONGHI, I994C: I8).

La respuesta a estos dos dilemas, sugiere el historiador, no debe buscarse en el plano de las ideas o los proyectos de los triunfadores de 1945-1946 (el peronismo como una variante del fascismo, su naturaleza autoritaria, etc.), y tampoco en el terreno de los debates y disputas que sólo interesaban a los círculos dirigentes y a los sectores más politizados de la población. En una política abierta a los influjos externos pero también tan idiosincrática como la argentina, esa respuesta tampoco va a encontrarse en las novedades que venían del Atlántico Norte (donde, por otra parte, luego de un cuarto de siglo de retroceso, para 1945 la balanza volvía a inclinarse en favor de la democracia representativa, que era precisamente la solución política impugnada en estas tierras). Por supuesto, el ocaso del liberalismo tampoco debe concebirse simplemente como el producto del agotamiento de una línea de avance histórico identificada con el ideal de una sociedad abierta a todos los influjos de la expansión europea, cuyo apogeo se vivió en las décadas de la gran inmigración y del boom exportador, y que desde la Gran Depresión comenzó a perder dinamismo (HALPERIN DONGHI, I987b: I55).

Las explicaciones colocadas en estos planos, sugiere el Halperin Donghi de La República imposible, no poseen la capacidad para dar cuenta del drástico cambio en la cultura política que el peronismo expresó y a la vez potenció, pero del que también se nutrió. Para comprender esta inflexión, advierte, no alcanza con centrar el problema en Perón ni en las elites que lo acompañaron, esos «factores tradicionales»-Iglesia y Ejército, pero también las oligarquías y la dirigencia conservadora y del interior del país- cuya importancia subrayan algunos estudios recientes 
(MACOR y TCACH, 2003: 3I). Ante todo, Halperin Donghi nos invita a dirigir la atención hacia la experiencia políticamente más significativa y más preñada de consecuencias de la «década infame»: la humillación que el régimen del fraude le infligió a las mayorías, y la cesura que ese modo de administrar el poder introdujo en la relación entre gobernantes y gobernados.

Es significativo que, de todos sus trabajos, La República imposible sea quizás aquel en el que Halperin Donghi más se esfuerza por recoger el testimonio y reconstruir la experiencia ya no de protagonistas de la vida pública sino de personajes más anónimos, de hombres y mujeres que vivieron esos años alejados de los grandes escenarios donde se dirimía la disputa por el poder. El punto de vista de estos sujetos es importante por cuanto nos ayuda a entender la naturaleza del vuelco que el régimen del fraude operó en las conciencia ciudadana. Y ello porque -contra las visiones que desestiman lo que el radicalismo significó en términos de inclusión popular en la vida pública- luego de que la apertura democrática diese lugar a «una auténtica experiencia de participación política» que contribuyó decisivamente a forjar sólidas identidades, la falsificación electoral y la «sórdida realidad» de la era del fraude dieron forma a un profundo «desapego ciudadano» que no sólo terminó privando de toda legitimidad al grupo dirigente (y condenándolo a partir de entonces a la irrelevancia política), sino que también dañó todo el legado ideológico e institucional forjado por los creadores de la Argentina moderna (HALPERIN DONGHI, 2004: 207, 269 y 272).

Hasta que fue demasiado tarde, sugiere La República imposible, el grupo gobernante no fue plenamente consciente de la erosión que el edificio político en su conjunto sufrió como consecuencia de la violencia cotidiana que supuso la falsificación electoral sobre esa sociedad que, tras la democratización de 1916-1930, ya no podía ser devuelta a la condición de minoridad cívica que ella misma había aceptado sin grandes protestas en los tiempos de la república oligárquica. De allí que fueran los «rasgos patológicos» de un régimen fraudulento que sólo podía funcionar sobre la base de la prepotencia y el cinismo los que, en definitiva, explican el rechazo del movimiento popular nacido en 1945, y del que fue su creador, jefe e intérprete, a admitir una herencia tan manchada. Pese a que, tras el derrumbe de 1930, la recuperación económica fue relativamente veloz y, para 1935, lo peor de la depresión había pasado, el fraude y los males a él asociados introdujeron una cesura entre los gobernantes y las mayorías que sólo pudo ser soldada con un nuevo contrato que no recogía sino jirones del anterior. Impugnado el legado 
acumulado desde el comienzo de la era constitucional, violentados los ideales que esas elites decían encarnar, los caminos del liberalismo, por una parte, y la política popular y el progresismo social, por la otra, terminaron apartándose, con gran daño también para el orden institucional.

Podemos concluir señalando que, visto a la luz del estado actual de los estudios sobre los años que median entre las presidencias de Yrigoyen y Perón, el trabajo de Halperin Donghi nos ofrece un sofisticado relato de la vida política, gracias al cual podemos alcanzar una mejor comprensión de sus hitos y sus recodos como de la manera en que fue percibida por sus grupos dirigentes. Todavía es demasiado pronto para decir qué tipo de relaciones pueden establecerse entre este complejo armazón y los estudios referidos a dimensiones y experiencias de la vida pública no contemplados en la mirada de Halperin Donghi que hoy concitan la atención de las nuevas generaciones de investigadores. Pero la contribución de este notable historiador también nos ofrece algo más, y cabe preguntarse de qué modos la nueva historiografía política puede contribuir a interrogar críticamente la gran hipótesis de claras resonancias populistas que recorre sus últimos textos sobre el período de entreguerras: quien quiera entender dónde está escondida la clave del «enigma argentino», del turbulento curso de la historia política de la segunda mitad del siglo, con su divorcio entre democracia liberal y reforma social, no puede pasar por alto lo sucedido en los años del régimen del fraude (HALPERIN DONGHI, 2008: 306). Pues fue entonces -y no en el más amplio e impreciso período de entreguerras-cuando, como consecuencia de las profundas humillaciones que los grupos dirigentes de la república del fraude le infringieron al sector mayoritario de la población, el proyecto constitucional nacido en tiempos de Mitre y Sarmiento se convirtió en una cáscara vacía. Este fracaso dio forma al escenario de desapego ciudadano y hostilidad hacia las instituciones de la república liberal que, en claro contraste con lo que sucedió entre Urquiza e Yrigoyen, incidió directamente sobre su trayectoria posterior. Para decirlo con sus propias palabras: en el medio siglo posterior a la «década infame» la Argentina experimentaría «varios otros modos de fracasar en el intento de vivir en democracia» $\mathrm{y}$ «en cada uno de esos fracasos era todavía posible rastrear las huellas de los años que el país había vivido prisionero de una República imposible» (HALPERIN DONGHI, 2004: 3I5). 


\section{Bibliografía}

ANSALDI, WALDO, PUCCIARELLI, ALFREDO Y VILLARUEL, CÉSAR (editores) (1993): Argentina en la paz de dos guerras, 1914-1945, Buenos Aires, Biblos. ALTAMIRANO, CARLOS (1992): «Hipótesis de lectura (sobre el tema de los intelectuales en la obra de Tulio Halperin Donghi)», Punto de Vista, 44. ALTAMIRAN0, CARLOS (2012): «La novela de formación de un historiador», Estudios Sociales, 42. ALTAMIRAN0, CARLOS (2016): «Halperin Donghi y los republicanos de las letras», en ALEJANDRO EUJANIÁN Y MARCELA TERNAVASIO (comps.), Halperin Donghi y sus mundos, Rosario, FHUMYAR. CAIMARI, LILA (2012):Mientras la ciudad duerme. Pistoleros, policías y periodistas en Buenos Aires, 1920-1945, Buenos Aires, Siglo XXI.

CAMARERO, HERNÁN (2007a): A la conquista de la clase obrera. Los comunistas y el mundo del trabajo en la Argentina, 1920-1935, Buenos Aires, Siglo XXI.

CAMARERO, HERNÁN (2007b): «Consideraciones sobre la historia social de la Argentina urbana en las décadas de 1920 y 1930: clase obrera y sectores populares", Nuevo Topo. Revista de historia y pensamiento crítico, $\mathrm{n}^{\circ} 4$.

DE PRIVITELLIO, LUCIANO, Y LOPEZ, IGNACIO (2015): «La década del treinta» (dossier 53), Polhis. Revista del Programa Interuniversitario de Historia Política.Disponible en: http://historiapolitica.com/ dossiers/dossier-la-decada-del-treinta/ (último ingreso: 09/06/2018).

DE PRIVITELLIO, LUCIANO (2012a):«La vida política», en CATTARUZZA, Alejandro (coord.), Argentina. Tomo 4. 1930-1960. Mirando hacia adentro, Madrid, Taurus/Mapfre.

DE PRIVITELLIO, LUCIANO (2012b), «¿Qué reformó la reforma? La quimera contra la máquina y el voto secreto y obligatorio", Estudios Sociales, n 43. DE PRIVITELLIO, LUCIANO (2003), Vecinos y ciudada- nos. Política y sociedad en la Buenos Aires de entreguerras, Buenos Aires, Siglo XXI.

DEVOTO, FERNANDO, Y FERRARI, MARCELA (comps.) (1994): La construcción de las democracias rioplatenses: proyectos institucionales y prácticas políticas, 1900-1930, Buenos Aires, Biblos. DEVOTO, FERNANDO (2002): Nacionalismo, fascismo y tradicionalismo en la Argentina moderna. Una historia, Buenos Aires, Siglo XXI.

FALCÓN, RICARDO (dir.) (2000): Democracia, conflicto social y renovación de ideas (1916-1930), Buenos Aires, Sudamericana.

FERNÁNDEZ IRUSTA, PABLO (2009): Alberto Barceló: Políticas públicas y caudillismo conservador en Avellaneda, 1909-1930, Tesis Doctoral inédita, Doctorado en Ciencias Sociales, Bernal, Universidad Nacional de Quilmes.

FERRARI, MARCELA (1996): «Triunfos electorales conservadores en tiempos de oficialismo radical: ¿condicionamiento estructural o influencia política? Provincia de Buenos Aires (1913-1934)», en MELÓN PIRRO, Julio y PASTORIZA, Elisa (comps.), Los caminos de la democracia. Alternativas y prácticas políticas, 1900-1943, Buenos Aires, Biblos.

FERRARI, MARCELA (2008): Los políticos en la república radical: prácticas políticas y construcción del poder (1916-1930), Buenos Aires, Siglo XXI. GERCHUNOFF, PABLO (2016): El eslabón perdido. La economía política de los gobiernos radicales, 1916-1930, Buenos Aires, Edhasa.

GONZÁLEZ ALEMÁN, MARIANNE (2014): «Ciudadanos en la calle. Violencia, virilidad y civilidad política en la campaña presidencial porteña de 1928», en: Hispanic American HistoricalReview, n 94. GORELIK, ADRIÁN (2013): «La década del treinta de María Teresa Gramuglio», ponencia presentada en la Mesa redonda "Celebración del itinerario 
crítico de María Teresa Gramuglio», en: III Congreso Internacional Cuestiones Críticas, Rosario, Centro Cultural Parque de España.

GUTIÉRREZ, LEANDRO, Y ROMERO, LUIS ALBERTO (1995): Sectores populares, cultura y política. Buenos Aires en la entreguerra, Buenos Aires, Sudamericana.

HALPERIN DONGHI, TULIO (1987a): «Intelectuales, sociedad y vida pública en Hispanoamérica a través de la literatura autobiográfica», en HALPERIN DONGHI, Tulio, El espejo de la historia. Problemas argentinos y perspectivas latinoamericanas, Buenos Aires, Sudamericana.

HALPERIN DONGHI, TULIO (1987b): «Liberalismo argentino y liberalismo mexicano: dos destinos divergentes», en:HALPERIN DONGHI, Tulio, EI espejo de la historia. Problemas argentinos y perspectivas latinoamericanas, Buenos Aires, Sudamericana.

HALPERIN DONGHI, TULIO (1992): «Backward Looks and Forward Glimpses from a QuincentennialVantage Point», en: Journal of Latin American Studies, vol. 24.

HALPERIN DONGHI, TULIO (1993): «EI lugar del peronismo en la tradición política argentina», en: AMARAL, Samuel y PLOTKIN, Mariano (comps.), Perón del exilio al poder, San Martín, Cántaro. HALPERIN DONGHI, TULIO ([1964] 1994a): Argentina en el callejón, Buenos Aires, Ariel.

HALPERIN DONGHI, TULIO (1994b): «Cuando no hay alternativas de fondo, el debate ideológico se hace poco interesante. Hoy no hay debates sobre el pasado porque no los hay sobre el presente», en: HORA, Roy y TRÍMBOLI, Javier (eds.), Pensar la Argentina. Los historiadores hablan de historia y política, Buenos Aires, El Cielo por Asalto. HALPERIN DONGHI, TULIO (1994c): La larga agonía de la Argentina peronista, Buenos Aires, Ariel. HALPERIN DONGHI, TULIO (1997): «EI populismo de
Manuel Fresco a la luz de su impacto electoral», en Darío Cantón y Jorge R. Jorrat (comps.), La investigación social hoy, Buenos Aires, Instituto de Investigaciones Gino Germani.

HALPERIN DONGHI, TULIO (2003): La Argentina y la tormenta del mundo. Ideas e ideologías entre 1930 y 1945, Buenos Aires, Siglo XXI.

HALPERIN DONGHI, TULIO (2004): La República imposible (1930-1945), Buenos Aires, Ariel.

HALPERIN DONGHI, TULIO (2008): Son memorias, Buenos Aires, Siglo XXI.

HALPERIN DONGHI, TULIO (2015): Las tormentas del mundo en el Río de la Plata. Cómo pensaron su época los intelectuales del siglo XX, Buenos Aires, Siglo XXI.

HORA, ROY (2015): «Repercusiones de la Gran Depresión en la sociedad argentina», en: DRINOT, Paulo y KNIGHT, Alan (coords.), La Gran Depresión en América Latina, México, Fondo de Cultura Económica.

HORA, ROY (2016): «El legado de Tulio Halperin Donghi», en Alejandro Eujanián y Marcela Ternavasio (comps.), Halperin Donghi y sus mundos, Rosario, FHUMYAR.

HORA, ROY (2005): «Una nación para el desierto argentino: algunas claves para su lectura», en: HALPERIN DONGHI, Tulio, Una nación para el desierto argentino, Buenos Aires, Prometeo. HOROWITZ, JOEL (2015): El radicalismo y el movimiento popular (1916-1930), Buenos Aires, Edhasa.

KARUSH, MATTHEW (2002): Workers or Citizens: Democracy and Identity in Rosario, Argentina (1912-1930), Albuquerque, University of New Mexico Press.

KORN, FRANCIS, Y ROMERO, LUIS ALBERTO (2006): Buenos Aires/entreguerras: la callada transformación, 1914-1945, Buenos Aires, Alianza. MACOR, DARÍ0, YTCACH, CÉSAR (2003): «El enigma per- 
onista», en: MACOR Darío y TCACH, César (comps.), PERSELLO, ANA VICTORIA (2004): El partido Radical. La invención del peronismo en el interior del Gobierno y oposición, 1916-1943, Buenos Aires, país, Santa Fe, Ediciones UNL. Siglo XXI.

LIDA, MIRANDA (2015): Historia del catolicismo en la Argentina. Entre el siglo XIX y el XX, Buenos Aires, Siglo XXI.

SARLO, BEATRIZ (1988): Una modernidad periférica: Buenos Aires, 1920 y 1930, Buenos Aires, Nueva Visión.

PALACI0, JUAN MANUEL (2010): «El primer peronismo TATO, MARÍA INÉS Y ROJKIND, INÉS (coords.) (2012) : «UsoS en la historiografía reciente: nuevas perspectivas de análisis», Iberomericana, vol. 10, nº 39. políticos del espacio público en la Argentina, 1890-1945», Polhis, vol. 5, no 9.

PALERM0, SILVANA (1998): «El Sufragio Femenino TORRE, JUAN CARLOS (1989): «Interpretando (una vez en el Congreso Nacional: Ideologías de Género y Ciudadanía en la Argentina (1916-1955)», en: Boletín del Instituto de Historia Argentina y Americana «Dr. Emilio Ravignani», no 16-17. PALERM0, SILVANA (2013): «En nombre del hogar proletario: Engendering the 1917 Great Railroad Strike in Argentina", en: Hispanic American Historical Review, no 93. más) los orígenes del peronismo», en: Desarrollo Económico, vol. 28, no 112.

VALDEZ, MARÍA JOSÉ (2012): «El plebiscito de Hipólito Yrigoyen: La campaña electoral de 1928 en la ciudad de Buenos Aires vista desde La Época», en: Población y Sociedad, nº 19.

ZANATTA, LORIS (1999): Perón y el mito de la nación católica. Iglesia y Ejército en los orígenes del peronismo (1943-1946), Buenos Aires, Sudamericana. 